Association for Information Systems

AIS Electronic Library (AISeL)

\title{
It's not that bad! Perceived Stress of Knowledge Workers During Enforced Working From Home due to COVID-19
}

\author{
Jana Mattern \\ Westfälische Wilhelms-Universität Münster \\ Simon Lansmann \\ Westfälische Wilhelms-Universität Münster \\ Joschka Hüllmann \\ Westfälische Wilhelms-Universität Münster
}




\title{
It's not that bad! Perceived stress of knowledge workers during enforced working from home due to COVID-19
}

\author{
Jana Mattern $^{1}$, Simon Lansmann ${ }^{1}$, Joschka Hüllmann ${ }^{1}$ \\ ${ }^{1}$ University of Muenster, Interorganizational Systems Group, Muenster, Germany \\ \{jana.mattern, simon. lansmann, joschka.huellmann\}@uni-muenster.de
}

\begin{abstract}
In March 2020, many organizations requested their employees to work from home to reduce their employees' risk of a COVID-19 infection. Research has suggested that working from home increases perceived stress due to blurring boundaries between work and private life. We examine whether this finding also holds for "enforced working from home" (EWFH) due to COVID-19 based on a four-week diary study in April and May 2020 with 37 participants from a German university. We suggest psychological detachment and communication overload as explaining variables for the relationship between EWFH and perceived stress. Our data show that EWFH leads neither to an inability to detach nor to communication overload. Similarly, EWFH does not increase participants' stress level. The findings show that working from home is a viable option for the future and that specifics of the EWFH setting, such as wide organizational support, can improve the working from home experience.
\end{abstract}

Keywords: COVID-19, Working from Home, Diary Study, Perceived Stress, Psychological Detachment, Communication Overload, Individual Focus Time

\section{Introduction}

Information and communication technologies (ICT) have enabled knowledge workers to work anytime and anywhere. Working from locations other than the physical office has been possible since the advent of personal telecommunication technology [1]. While working from home or at clients' sites has been popular among technology and management consultants, other professions have mostly worked from the physical office. In 2014, only $22 \%$ of German employees worked at least partly from home [2]. Insufficient technical equipment, companies' concerns about reduced productivity because of less social and informational exchange with colleagues and supervisors, as well as the manager's willingness to allow working from home are among the strongest predictors for the number of employees who work from home [2, 3].

At the beginning of the COVID-19 pandemic, governments mandated social distancing policies. Organizations had to send most of their employees to work from home to reduce the infection risk [4], resulting in "enforced working from home" (EWFH) [5]. One third of all employees in Germany worked from home at the beginning of the pandemic in April 2020 [6]. First survey studies on the impact of 
EWFH show that this change has provided a welcome acceleration of the digitalization of work as technical equipment [7]. Moreover, policies and routines needed for digital work have been developed in days rather than years [5, 6]. Remarkably, employees feel more productive and less stressed $[6,8]$. These initial findings contradict prior literature suggesting that working from locations other than the office increases perceived stress [9] by blurring boundaries between work and private life [10].

Our study contributes to the emerging body of research in information systems studying the behavioral, societal, and organizational aspects of COVID-19 [11]. Our research question is: How does enforced working from home due to COVID-19 influence knowledge workers' perceived stress?

To identify factors that explain why employees might experience stress during EWFH, we consult the academic literature for variables that mediate the influence of working from home on perceived stress. We acknowledge that various factors might work as mediators for the relationship between EWFH and perceived stress. However, for the scope of this paper, we focus on psychological detachment [12] and communication overload [13] as explanatory variables for two reasons: (1) EWFH requires increased work-related ICT use, which has been found to result in an extended availability to work [14]. Due to technology-enabled prolonged working hours, we expect that work spills over to private life, resulting in difficulties to detach from work. (2) Recent studies found an increased volume of electronic communication during EWFH [6, 8]. It has been suggested that employees might compensate the lack of physical visibility by increased electronic communication with colleagues and managers [15]. When the amount of electronic communication exceeds communication needs, employees can suffer communication overload. To account for the differences between EWFH and prior working from home arrangements, we consider additional worries about the COVID-19 pandemic.

To answer our research question, we conduct a mixed method diary study with employees from a German university during the early phase of the country's lockdown in April and May 2020. Our study contributes to the growing body of knowledge that examines the effects of EWFH due to COVID-19 on employees' well-being [6]. In particular, we quantify to which extent the two factors (1) perceived ability to detach from work during non-work hours and (2) communication overload predict the emergence of stress in the COVID-19 situation. Our findings inform the future organization of work that is developing based on the reflections of the pandemic.

The remainder of the paper is as follows: At first, we describe related work regarding (enforced) working from home and perceived stress, psychological detachment, and communication overload. After that, we describe our study design and results. Then, we discuss the findings against the backdrop of recent COVID-19 studies. Before concluding our paper, we consider limitations and avenues for future research. 


\section{Theoretical Background}

\section{1 (Enforced) Working From Home and Stress}

Working from home is a specific case of telecommuting or telework, which is "a flexible work arrangement that allows employees, usually with the aid of electronic communication devices, to accomplish their work in various locations instead of a fixed, central worksite" ([16], p. 386). This way of working was introduced in the last quarter of the $20^{\text {th }}$ century to decrease real-estate costs and air pollution, and allow for a healthy work-family balance [3]. In the context of working from home, employees do not work from various locations but from their homes. Due to the wide distribution of mobile devices and ICT, working from anywhere is easier than ever before [17]. However, while research on general telework is extensive, the specific context of working from home has been researched only to a limited extent and has been equated with telework (e.g., [5]). Our study examines whether the empirical findings regarding telework hold for the working from home environment and specifically for EWFH due to the COVID-19 pandemic.

Academic research on telework has yielded ambivalent results when examining its effects for employees [18]. Main benefits comprise increased productivity and autonomy, balanced work and private life, reduced commute, reduced overheads for employers, and an increased skill base [19, 20]. Reported problems are, amongst others, social isolation, presenteeism, lack of support, career disadvantages, blurring boundaries between work and private life, and technostress [19, 21].

The negative effects of telework have been complemented by research on ICTenabled working from home, such as extended availability for work after work hours [22], increased work-life conflict [23, 24], as well as role overload and stress [10, 25]. We expect EWFH to exacerbate these adverse effects as EWFH also impacts employees not having prior experience with working from home. Those employees "have to cope with rapid and fundamental changes in the nature of work environments and they are required to keep pace with technological changes." ([26], p. 141). Therefore, our first hypothesis is:

\section{H1: EWFH due to COVID-19 increases daily perceived stress.}

\subsection{Psychological Detachment}

Blurred work-life boundaries because of the increased use of ICT for work explain the negative effects of working from home on employees' health and well-being [21, 25]. Employees are extensively tied to work through work-related ICT [27]. They continuously face the stressors inherent in their work, which impedes their ability to recover [28] and increases their stress level [29]. Recovery research has positioned psychological detachment as a mediating factor for the relationship between workstressors and employees' stress levels [12]. Psychological detachment means "refraining from job-related activities and mentally disengaging from work during time off the job" ([12], p. 72). The ability to detach has gained importance in modern, 
distributed work environments, especially in working from home [30]. A collocation of work and private domains renders gaining mental distance from work difficult due to the lack of physical boundaries [25]. While in physical work settings employees can leave work behind by leaving the office and shutting the door, working from home means that work is always present, for example, when seeing the laptop sitting on the kitchen desk. Since ICT allow employees to receive and send messages anywhere and at any time, managers and clients expect an extended availability [31]. Thus, ICT use for work impedes employees' ability to detach, increasing their stress levels [14].

In the situation of EWFH due to COVID-19, employees know that everyone works from home so that strict office times are obsolete. Work is only "one click away" for everyone, blurring the boundaries between work and private life. As clear boundaries cease to exist, employees might be less confident in their ability to detach from work. Accordingly, our second hypothesis is:

H2: Daily perceived detachment ability mediates the relationship between EWFH and daily perceived stress.

H2a: EWFH decreases daily perceived detachment ability.

H2b: Daily perceived detachment ability decreases daily perceived stress.

\subsection{Communication Overload}

Electronic communication bridges physical distance. It enables collaboration between employees at different locations [32], rendering it necessary while working from home [27]. In general, employees have different needs for communication volumes depending on their role. These needs range from low volumes for "silent workers" to intense volumes for "communicators" [33]. Before the COVID-19 pandemic, employees often worked from home to complete tasks that benefit from uninterrupted work [34]. This specific mode of work has been labeled as "deep work" or, more commonly used, "focus time": episodes of distraction-free individual focus [35].

During EWFH, working from home serves another primary purpose. It is no longer a location designed for the specific mode of individual focus work but the default work location. As EWFH limits physical, in-person communication, we conjecture that employees compensate for this limitation by drawing more intensively on electronic communication. To facilitate electronic communication, organizations use enterprise collaborations platforms, such as Microsoft Teams, more extensively during EWFH [7, 36]. Although the use of such platforms enables seamless collaboration, it can also increase employees' overall communication volumes. When employees spend too much time in communicative episodes and do not have enough time for individual focus work, they experience lower performance and reduced well-being [37]. Research has demonstrated that too much electronic communication increases employees' stress levels $[38,39]$.

To operationalize being overloaded with electronic messages, we use the construct communication overload [13], which is defined as "a measure of the extent to which, in a given period of time, an organization's member perceives more quantity, complexity, and/or equivocality in the information than an individual desires, needs, or 
can handle in the process of communication" ([40], p. 8 as cited in [41], p. 2). Hence, our third hypothesis is:

H3: Daily communication overload mediates the relationship between EWFH and daily perceived stress.

H3a: EWFH increases daily communication overload.

H3b: Daily communication overload increases daily perceived stress.

Our research model, including all hypotheses, is illustrated in Figure 1.

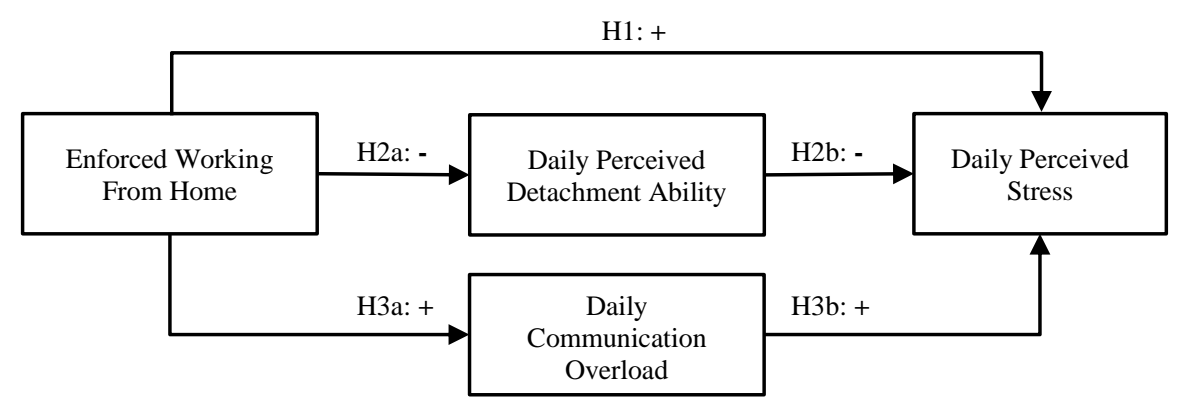

Figure 1. Research Model

\section{$3 \quad$ Method}

\subsection{Procedure and Participants}

We recruited our study participants via a mailing list comprising all staff members of the business and economics faculty at a large German university. Our sample consisted of knowledge workers because most of them worked in research and teaching (see Section 4.1), tasks that require a high amount of intellectual work. These employees exert autonomy regarding when and how they work, mainly restricted by external deadlines resulting from projects or publication processes. The university allowed employees to work from home before the COVID-19 pandemic, depending on individual agreements with supervisors. Most of the study participants had the technical equipment required for working from home, such as laptops, before the pandemic. However, $38 \%$ had never and only $5 \%$ had regularly worked from home before. Their job often required them to collaborate with (international) colleagues so that $70 \%$ had used at least one video conferencing tool before the pandemic. Our sample displayed an increased number of meetings in the first weeks of the pandemic. In the first week of our study, $60 \%$ reported to have 1-2 additional meetings and $32 \%$ reported to have more than 3 additional meetings per week compared to the time before the pandemic. These numbers remained stable throughout our data collection period.

We collected the data between April 28 and May 21, 2020. During this period, the participants worked from home to reduce infection risk. We collected the data via online questionnaires. The first questionnaire included questions regarding demographics, family and living situation, previous working from home experience, 
and experience with electronic collaboration tools. Furthermore, we included the control variables of Sense of Coherence (SoC) and attitude towards IT. In the end, participants entered their email address in case they wanted to go on with the study.

Participation in the study was voluntary. 55 participants filled out the first questionnaire. We ensured anonymity by developing a personal code in the first questionnaire, which allowed no identification of the email address. A link to the consecutive questionnaires was sent to the participants twice a week (Tuesday and Thursday). The participants were requested to fill out the questionnaire on the respective day at the end of their work. In each questionnaire, participants had to indicate whether their working situation had changed (percentage of working from home, tasks, technical equipment). We chose the diary design to examine whether the employees adapted to working from home. Compared to other diary studies that usually examine one week (e.g., [42, 43]), we chose a long period of four weeks to account for changes in the recommendations and decrees of the federal state government. Indeed, after two weeks, the government relaxed the restrictions, which we captured with additional questions. In total, 37 participants filled out the first questionnaire, and at least five of the eight diaries, which comprises the final sample for our study.

\subsection{Measures}

The complete questionnaire is available from the authors. All items were in German and answered on a 5-Point Likert-Scale ( $1=$ strongly disagree to $5=$ strongly agree $)$.

Enforced Working From Home was measured through the question "What percentage of your work do you work from home in the current situation?" $(1=0 \%$ to $5=100 \%$ ). We controlled for changes in the extent of working from home by asking this question in each diary entry, however, we did not find any significant changes over the four weeks. Therefore, we decided to include the aggregate of entries in the analysis.

Daily Perceived Detachment Ability was measured with two adapted items from the detachment subscale of the Recovery Experiences Questionnaire [44]. We asked our participants to answer the questionnaire after having finished their workday. Therefore, the questions captured the perceived ability to detach in the evening instead of the actual detachment experience, which is usually measured before going to bed. The scale was adjusted for daily measurement and for measuring the confidence regarding detachment (e.g., "I am confident that I will forget about work today in my free time after work."). Cronbach's alpha ( $\alpha$ ) of the scale varied from .862 to .929 , with a mean of .902 over the four weeks.

Daily Communication Overload was measured with four adapted items from the communication overload scale by Cho et al. [13]. The scale was adjusted for daily measurements and addressed all electronic communication means (e.g., "Today, I felt that I had spent too much time on electronic communication (calls, virtual meetings, emails, chats, SMS, etc.”). $\alpha$ varied from .856 to .946 , with a mean of .905 .

Daily Perceived Stress was measured with the four-item-version of the perceived stress scale [45]. The scale was adjusted for daily measurements (e.g., "Today, how often have you felt that things were going your way?"). $\alpha$ varied from .661 to .896 , with a mean of .804 . 
Attitude Towards IT was measured with two items from the personal innovativeness in the IT domain scale by Agarwal and Prasad [46] $(\alpha=.720)$.

Sense of Coherence (SoC) was measured with the 13 item version of the Sense of Coherence Scale (SOC-13) [47]. Items were answered on a 5-Point Likert-Scale $(1=$ never or seldom to $5=$ very often) or with the respective anchors (e.g., $1=$ under/overestimate to $5=$ estimate correctly) $(\alpha=.784)$.

Daily COVID-19 Worries were measured to account for additional stressors while working from home due to the unusual pandemic situation. This self-designed scale comprised health-related worries, technical and financial worries and worries concerning the working situation (e.g., "Today, I was burdened by the spatial situation of my workplace.”). Information regarding Principal Component Analysis (PCA) is available from the authors. $\alpha$ varied from .650 to .819 with an average of .715 .

Daily Open Reflection was measured by an open text field that asked the participants to reflect on their daily situation ("Please describe how you are feeling today."). In the last questionnaire, we also asked for an overall reflection of the four weeks spanning the study ("If you reflect on the last four weeks in total, what are your take-aways?"). These reflections provided the qualitative data used in our analysis.

\subsection{Analysis}

Given the repeated measurements were nested within individuals, we specified a twolevel random intercept model with a random slope for time. The first level consisted of data at the day level $(\mathrm{N}=185-296$ study occasions). The second level consisted of individual persons $(\mathrm{N}=37)$. We applied multi-level analysis with SPSS (version 25). Predictor variables at the day level (i.e., perceived psychological detachment ability, communication overload, COVID-19 worries) were centered to the individual mean, while predictor and control variables at the person level (i.e., SoC, prior working from home experience, attitude towards IT) were centered to the grand mean. The control variables attitude towards IT, SoC, and COVID-19 worries had significant correlations with the outcome variable perceived stress and were therefore included in the analysis. Controlling for prior experience with working from home (i.e., "How often did you work from home before the COVID-19 pandemic?") did not yield any significant relationships.

We analyzed the qualitative data according to thematic qualitative text analysis [48] and used MAXQDA for coding. Guided by our theoretical framework and the measures employed in the questionnaire, we developed six initial codes during a first coding cycle: perceived stress, detachment, communication overload, Corona worries, working from office and family situation. The first three codes captured our understanding of the concepts depicted in Chapter 2. We applied the code Corona worries for all text passages where the participants expressed feelings regarding the general pandemic situation beyond work topics. We used working from office to code all statements where participants described that they chose to work from the office instead of working from home. The code family situation indicated participants' accounts concerning family care duties. 
The second coding cycle yielded two additional codes: hardware/software problems to account for problems with the used equipment including internet access, and the it's not that bad code for accounts where EWFH had positive developments and outcomes. Table 1 summarizes the code system and provides examples quotes.

Table 1. Qualitative Codes and Example Quotes

\begin{tabular}{|c|c|}
\hline Code & Example Quote \\
\hline Perceived Stress & $\begin{array}{l}\text { "Today I had a stressful morning with many digital } \\
\text { meetings." (ID 7) }\end{array}$ \\
\hline Detachment & $\begin{array}{l}\text { "Since there is still a busy day ahead of me, I am already } \\
\text { looking forward to my evening sports program." (ID 36) }\end{array}$ \\
\hline Communication Overload & $\begin{array}{l}\text { "The 'email flood' is so prevalent that you have to organize } \\
\text { yourself very well to keep an eye on everything." (ID 30) }\end{array}$ \\
\hline Corona Worries & $\begin{array}{l}\text { "Corona news really bother me, so I try to avoid this } \\
\text { information in my daily routine." (ID 15) }\end{array}$ \\
\hline Working from Office & $\begin{array}{l}\text { "Today, I had a few appointments for which I went to the } \\
\text { office instead of WFH, because of a better focus and } \\
\text { silence." (ID 7) }\end{array}$ \\
\hline Family Situation & "WFH is ok if no kids are jumping around." (ID 20) \\
\hline Hardware/Software Problems & $\begin{array}{l}\text { "Frustrated because Skype is not working and no solution } \\
\text { has been found yet." (ID 10) }\end{array}$ \\
\hline It's not that bad & "WFH is no longer exhausting, it is just normal." (ID 6) \\
\hline
\end{tabular}

\section{$4 \quad$ Results}

\subsection{Descriptive Statistics}

The gender of participants was equally distributed with 19 males (51.4\%) and 18 females (48.6\%). 54.1\% of the participants were between 25 and 34 years old, $3 \%$ were younger than 25 years old, $35 \%$ were between 35 and 54 years old, and $8 \%$ were older than 54 years old. $73 \%$ worked in research and teaching, $21.6 \%$ represented administrative staff, and $5.4 \%$ worked in IT. The majority of the participants lived together with another person $(51.4 \%)$ or with more than two persons $(29.7 \%) .21 .6 \%$ lived together with at least one child but only $8.1 \%$ with a child younger than 3 .

Regarding the working situation at home, $32.4 \%$ worked in a separate room dedicated for work, $13.5 \%$ in a separate room that had been transformed into an office setup (e.g., guest room), 32.4\% worked from a desk but not in a separate room (e.g., desk in the living room), and $21.6 \%$ worked at a table other than a desk, for example, a kitchen or dining table. Table 2 displays descriptive statistics and bivariate correlations.

\subsection{Hypotheses Testing}

To test whether EWFH increased daily perceived stress (H1), we compared the multilevel model containing EWFH and the control variables daily COVID-19 worries, SoC, and attitude towards IT to the null model that included only the intercept. The multilevel model showed a significant improvement over the null model $(\Delta-2 \mathrm{x} \log =64.692$, 
$\mathrm{df}=4, \mathrm{p}<.001$ ). The estimate of EWFH was not significant (see Table 3), rejecting hypothesis 1 . However, the estimates for the control variables SoC, attitude towards IT, and daily COVID-19 worries were significant.

Since we found no direct relationship between EWFH and daily perceived stress, we rejected hypothesis 2 regarding an indirect effect of EWFH via daily perceived detachment ability on daily perceived stress. However, according to Kenny et al. [49], testing for an indirect effect is still possible when both the predictor and the outcome variable are significantly related to the mediator. Therefore, we tested the multi-level model with EWFH and the significant control variables as predictors of daily perceived detachment ability, which showed a significant improvement over the null model $(\Delta$ $2 \mathrm{x} \log =30.221, \mathrm{df}=4, \mathrm{p}<.001$ ). However, the estimate of EWFH was not significant (see Table 4), rejecting hypothesis 2a. Only the estimate for daily COVID-19 worries was significant. The multi-level model with daily perceived detachment ability and the control variables predicting perceived stress showed a significant improvement over the null model $(\Delta-2 \mathrm{x} \log =70.862, \mathrm{df}=4, \mathrm{p}<.001)$. The estimate of daily perceived detachment ability was significant (see Table 3 ), supporting hypothesis $2 \mathrm{~b}$. Since only the mediator-outcome path was significant, hypothesis 2 could not be supported.

Similar to hypothesis 2, we tested whether EWFH and daily perceived stress are significantly related to daily communication overload as a mediator. The multi-level model with EWFH and the significant control variables as predictors for daily communication overload showed no significant improvement over the null model $(\Delta$ $2 \mathrm{x} \log =8.758, \mathrm{df}=4, \mathrm{p}=.067$ ). The estimate of EWFH was not significant (see Table $5)$, rejecting hypothesis 3 a. The multi-level model with daily communication overload and the control variables as predictors of daily perceived stress showed significant improvement over the null model $(\Delta-2 \mathrm{x} \log =63.786, \mathrm{df}=4, \mathrm{p}<.001$. $)$. The estimate of daily communication overload was not significant (see Table 3 ), thereby rejecting hypothesis $3 \mathrm{~b}$. Since both the predictor-mediator and the mediator-outcome path were not significant, hypothesis 3 could not be supported.

Figure 2 depicts an overview of the results regarding each hypothesis.

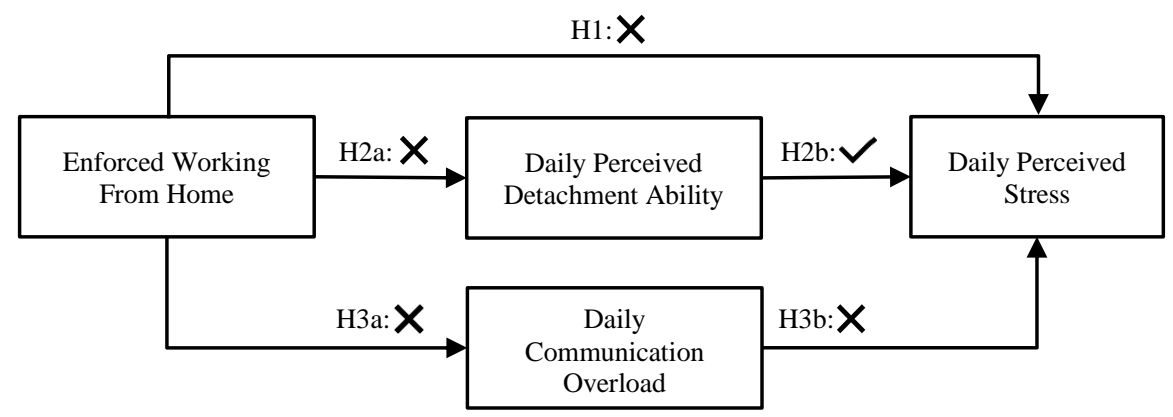

Figure 2. Research Model with Results 
Table 2. Descriptive Statistics $\left\{\mathrm{M}=\mathrm{Mean}, \mathrm{SD}=\right.$ Standard Deviation, ${ }^{*} \mathrm{p}<.05, * * \mathrm{p}<.01,{ }^{1}$ reversed score, ${ }^{2}$ based on mean scores across the

\begin{tabular}{llcccccccccc}
\multicolumn{10}{c}{ eight days that the study took place } \\
\hline & Variable & $M$ & $S D$ & 1 & 2 & 3 & 4 & 5 & 6 & 7 & 8 \\
\hline 1 & Enforced Working From Home & 4.32 & .75 & - & .03 & .08 & .12 & -.12 & -.15 & .21 & -.14 \\
2 & Daily Perceived Detachment Ability $^{2}$ & 3.31 & .94 & & - & .00 & .03 & $-.37^{*}$ & .09 & -.01 & -.30 \\
3 & Daily Communication Overload $^{2}$ & 2.24 & .82 & & & - & $.33^{*}$ & .12 & -.13 & .14 & .28 \\
4 & Daily Perceived Stress & 2.13 & .58 & & & & - & $-.38^{*}$ & $-.52^{* *}$ & -.05 & $.51^{* *}$ \\
5 & Attitude towards IT & 3.34 & .91 & & & & & - & .01 & .17 & -.10 \\
6 & Sense of Coherence $^{1}$ & 3.25 & .76 & & & & & & - & -.01 & $-.35^{*}$ \\
7 & Working From Home Experience $^{*}$ & 1.86 & .92 & & & & & & - & -.12 \\
8 & Daily COVID-19 Worries $^{2}$ & 2.08 & .48 & & & & & & & -
\end{tabular}

Table 3. Multi-Level Results of Control Variables, Enforced Working from Home (EWFH), Daily Perceived Detachment Ability (DetAb), Daily Communication Overload (ComOv) and Daily Perceived Stress (PS) $\left\{{ }^{*} \mathrm{p}<.05, * * \mathrm{p}<.01, * * * \mathrm{p}<.001,{ }^{1}\right.$ reversed score

\begin{tabular}{|c|c|c|c|c|c|c|c|c|c|c|c|c|}
\hline \multirow[t]{2}{*}{ Variable } & \multicolumn{3}{|c|}{ Null Model } & \multicolumn{3}{|c|}{ Predictor Model (H1) } & \multicolumn{3}{|c|}{ Predictor model $(H 2 b)$} & \multicolumn{3}{|c|}{ Predictor model (H3b) } \\
\hline & Est. & $S E$ & $t$ & Est. & $S E$ & $t$ & Est. & $S E$ & $t$ & Est. & $S E$ & $t$ \\
\hline Intercept (PS) & 2.13 & .095 & $22.318 * * *$ & 2.12 & .077 & $27.571 * * *$ & 2.117 & .075 & $28.251 * * *$ & 2.123 & .076 & $27.946 * * *$ \\
\hline Sense of Coherence ${ }^{1}$ & & & & -.40 & .105 & $-3.764 * *$ & -.40 & .101 & $-3.92 * * *$ & -.397 & .102 & $-3.879 * * *$ \\
\hline Attitude towards IT & & & & -.227 & .09 & $-2.62 *$ & -.234 & .084 & $-2.80 * *$ & -.229 & .085 & $-2.700 *$ \\
\hline COVID-19 Worries & & & & .27 & .09 & $2.88 * *$ & .234 & .097 & $2.423 *$ & .274 & .097 & $2.837 * *$ \\
\hline EWFH & & & & .015 & .09 & .16 & & & & & & \\
\hline $\operatorname{Det} A b$ & & & & & & & -.123 & .044 & $-2.820 *$ & & & \\
\hline ComOv & & & & & & & & & & .033 & .048 & .701 \\
\hline$-2 x \log$ & \multicolumn{3}{|c|}{460.149} & \multicolumn{2}{|c|}{395.457} & & \multicolumn{2}{|c|}{389.287} & \multicolumn{4}{|c|}{396.364} \\
\hline
\end{tabular}

16th International Conference on Wirtschaftsinformatik,

March 2021, Essen, Germany 
Table 4. Multi-Level Results of Control Variables, Enforced Working From Home (EWFH), and Daily Perceived Detachment Ability (DetAb) $\left\{{ }^{*} \mathrm{p}<.05,{ }^{1}\right.$ reversed score $\}$

\begin{tabular}{lcccccc}
\hline Variable & \multicolumn{2}{c}{ Null Model } & \multicolumn{4}{c}{ Predictor Model $(\mathrm{H} 2 a)$} \\
\hline & Estimate & SE & $t$ & Estimate & $S E$ & $t$ \\
\hline Intercept (DetAb) & -.001 & .041 & -.021 & -.035 & .041 & -.855 \\
Sense of Coherence ${ }^{1}$ & & & & .013 & .057 & .226 \\
Attitude towards IT & & & & -.033 & .045 & -.715 \\
COVID-19 Worries & & & & -.331 & -.135 & $-2.449^{*}$ \\
EWFH & & & & .008 & .051 & .148 \\
$-2 \mathrm{x} \mathrm{log}$ & 563.977 & & & 533.756 & & \\
\hline
\end{tabular}

Table 5. Multi-Level Results of Control Variables, Enforced Working from Home (EWFH), and Daily Communication Overload (ComOv) $\left\{{ }^{1}\right.$ reversed score $\}$

\begin{tabular}{|c|c|c|c|c|c|c|}
\hline \multirow[t]{2}{*}{ Variable } & \multicolumn{3}{|c|}{ Null Model } & \multicolumn{3}{|c|}{ Predictor Model ( $\mathrm{H} 3 \mathrm{a})$} \\
\hline & Estimate & $S E$ & $t$ & Estimate & $S E$ & $t$ \\
\hline Intercept (ComOv) & .002 & .037 & .043 & .008 & .040 & .198 \\
\hline Sense of Coherence ${ }^{1}$ & & & & -.016 & .056 & -.284 \\
\hline Attitude towards IT & & & & .007 & .044 & .162 \\
\hline COVID-19 Worries & & & & .167 & .127 & 1.322 \\
\hline EWFH & & & & -.007 & .050 & -.118 \\
\hline$-2 x \log$ & 509.911 & & & 501.153 & & \\
\hline
\end{tabular}

\subsection{Qualitative Analysis}

Perceived Stress. Overall, participants described situations as stressful that were related to approaching deadlines and episodes of back-to-back meetings. Except for one participant who described the general work situation as demanding ("The work situation feels like a marathon: the workload remains (too) high." ID 34), we did not find statements providing evidence for a high stress level of our study participants.

Detachment. Problems with detachment were rarely mentioned but present ("Somehow the work went into the end of the day rather seamlessly [...] at some point I wandered from my desk to the couch (both in the living room), which at least provided a change of location, but the laptop was always with me." ID 6). Participants reported that it was easier to stay mentally connected to work due to the possibility to "quickly look things up" (ID 30) while working from home.

Communication Overload. Since the majority of our participants worked in research and teaching, their typical work activities comprised reading, writing, or thinking ("[it is] basically doing a lot of quiet work alone." ID 16). The participants did not perceive the decrease of in-person communication and the changes in their volume of electronic communication as problematic. Instead, they were able to engage in individual focus time ("Today was an almost meeting-free day and the opportunity to concentrate on essays." ID 34). Only two participants explicitly named an increased email volume as demanding. Some participants reported the opposite of communication overload. For them, any form of electronic communication, such as team meetings, was

16th International Conference on Wirtschaftsinformatik, March 2021, Essen, Germany 
a welcome social interaction ("Somehow I'm looking forward to these meetings - no matter what the content is." ID 17).

Corona Worries. These worries were mentioned mainly with reference to children and the reduced opportunity to rely on family members, such as grandparents, without increasing the infection risk. Some participants reported that the uncertainty about the future negatively affected their sleep quality ("I sleep badly and worry about the future." ID 4).

Working from Office. For specific work activities, participants perceived a need to work from office since they found it difficult to conduct them at home ("Today I went to the office, because I had to clarify things in person and sign documents." ID 19).

Family Situation. The dominant stressor resulting from EWFH was taking care of children ("[...] this double burden [gnaws] on the nerves, one is stressed and sometimes has the feeling that one is not doing justice to work or family life." ID 29).

Hardware/Software Problems. Next to taking care of children and the noisy environment at home, participants mentioned hardware/software issues as primary reasons to work from office ("Today was stressful because I had to drive to the institute due to the poorly performing internet at home." ID 2).

It's not that bad. Many participants without prior WFH experience reported positive aspects ("In fact, I like working from home better than I thought beforehand, and a certain amount of anxiety about technologies and how to use them has turned out to be unfounded over time." ID 17). Whether or not the home was the preferred work location depended on the task structure ("I have become more aware that working from home is nothing for me, except for the larger tasks where you have to concentrate on one thing." ID 26) as well the spatial and family situation at home; that is, having a separate room for work as well as options for childcare.

\section{Discussion}

Our study sheds light on how EWFH due to COVID-19 influences the perceived stress level of knowledge workers. We find that, overall, our study participants do not experience more stress while working from home. Although this finding contradicts academic literature on the adverse effects of working from home (e.g., [10]), it supports recent findings on the perceptions of knowledge workers regarding EWFH due to COVID-19 [6]. It seems that employees have adapted swiftly to EWFH. Contrary to our assumptions, we do not find evidence that the blending of work and private life or being overloaded by electronic communication increase the perceived stress level. Instead, general worries about the COVID-19 situation lead to a higher stress level.

\subsection{Children at Home and Social Norms at Work}

Characteristics of our sample can explain our findings. Working at a public university, our participants do not have to fear financial or even job loss. The majority of our participants live alone or with their partners, and only few have young children. As our qualitative analysis shows that childcare is the predominant stressor in the EWFH 
setting, it is not surprising that our sample displays a low stress level in the quantitative data. Another reason for the contradiction between our findings and the academic literature is rooted in the specific EWFH setting. EWFH impacts the whole workforce and not only parts of it, as it was the case for prior working from home arrangements. Prior research has reported that employees who often work from home experience power distances compared to their peers who work from the physical office, which results in feelings of social isolation [50] and perceptions of a lack of organizational support [51]. In an EWFH setting, everyone is working from home so that these "marginalizations" [5] do not exist.

Our quantitative data demonstrates that the perceived inability to detach from work during non-work hours leads to an increased stress level, thereby supporting previous literature [14]. However, our sample does not depict problems in detaching from work. Moreover, we do not find a significant relationship between EWFH and perceived ability to detach. This finding contradicts academic literature [24] and current studies stating that EWFH due to COVID-19 impedes the ability to draw the line between work and family life [6]. Apparently, other factors not included in our study account for an inability to detach. Prior research has suggested, for example, that social norms regarding an extended availability for work predict whether employees work beyond their official working hours $[24,52]$.

\subsection{Outeraction and Individual Focus Time}

While recent surveys have reported that the goal of EWFH to minimize physical contact increased the overall volume of electronic communication [6,8], we do not find evidence for an increased volume in our sample. Conversely, both qualitative and quantitative analyses reveal that our sample does not experience stress due to communication overload.

Our qualitative data explains why the number of meetings has not increased: Participants report coordination overhead resulting from the need to schedule each meeting and negotiate availability instead of conducting physical ad-hoc meetings at the desk of a colleague. This overhead has been called "outeraction", as preambles for periods of interaction [53]. These virtual outeractions require more effort than "a tap on the shoulder" in the physical office, reducing the number of meetings, above all of ad-hoc meetings [5].

Furthermore, the need for communication varies for different job roles. Our findings suggest that the task structure of university employees responsible for research and teaching does not require extensive communication and coordination. In contrast, our qualitative data show that they benefit from individual focus time because their work mainly requires solving complex problems and preparing manuscripts or lectures. Others, whose task structure consists of more communication, may have suffered from too much communication in the EWFH situation (cf. [6]). 


\section{$6 \quad$ Limitations and Future Research}

Although we included questions about the physical and technical equipment in our questionnaire, we did not ask in detail about the characteristics of the individual work setting that could explain differences between prior working from home arrangements and EWFH. As the COVID-19 context provides a specific, enforced work setting, findings should be considered carefully when drawing general conclusions for the working from home literature.

Future studies should examine additional variables, such as ergonomic factors, relationships to members of the household, and the distribution of domestic tasks. As we did not find a relationship between EWFH and the perceived ability to detach, future research is needed that examines which factors of working from home result in particular outcomes. As stated above, social norms present a promising avenue.

We researched a relatively homogenous sample in terms of age and position in the organizational hierarchy. Future research should consider career ambitions, responsibilities, and leadership positions that might result in staying attached to work while working from home. A more heterogeneous sample will allow studying the role of childcare for perceived stress and how differences in task structures lead to different perceptions of working from home.

\section{Conclusion}

Our study contributes to the academic literature that examines the role of working from home for the perceived stress of knowledge workers by emphasizing that "it's not that $b a d$ ". We apply a unique longitudinal diary study design for researching the impacts of EWFH. We believe that this specific design is beneficial for capturing dynamic changes in the working from home situation resulting from changing lockdown measures. Diary studies capture participants' adaption to the new EWFH setting.

We find that EWFH does not lead to an increased perceived stress level, suggesting (1) that knowledge workers can adapt to the rapid shift from a physical office to the home office, (2) that knowledge workers in an EWFH environment face fewer stressors compared to prior working from home arrangements (e.g., better organizational support, no marginalization of home office workers), and (3) that the benefits of working from home, such as time savings due to less commuting time, outweigh potential negative effects, such as blurred work-life boundaries. Our study, therefore, calls for research taking a deep dive into the specifics of the EWFH environment compared to prior working from home settings as well as into individual coping strategies of employees to explain the effects for employees' well-being. Benefits from the EWFH phase should be kept in a voluntary working from home setting.

Our study further suggests that organizations should consider to allow, or even encourage, employees to continue working from home in the future, at least to a certain extent. We believe that especially job roles that require longer stretches of individual focus work (compared to roles with embedded high communication needs) benefit from working from home. 


\section{References}

1. Bélanger, F.: Workers' propensity to telecommute: An empirical study. Inf. Manag. 35, 139-153 (1999).

2. Bitkom Research: Vier von zehn Unternehmen setzen auf Homeoffice, https://www.bitkom.org/Presse/Presseinformation/Vier-von-zehn-Unternehmensetzen-auf-Homeoffice, last accessed 2020/12/08.

3. Bailey, D.E., Kurland, N.B.: A review of telework research: Findings, new directions, and lessons for the study of modern work. J. Organ. Behav. 23, 383-400 (2002).

4. Alipour, J.-V., Fadinger, H., Schymik, J.: My home is my castle: The benefits of working from home during a pandemic crisis. Evidence from Germany. ifo Work. Pap. 329, 1-48 (2020).

5. Waizenegger, L., McKenna, B., Wenie, C., Taino, B.: An Affordance Perspective of Team Collaboration and Enforced Working from Home During COVID-19. Eur. J. Inf. Syst. 29, 429-442 (2020).

6. DAK-Gesundheit: Digitalisierung und Homeoffice in der Corona-Krise, https://www.dak.de/dak/bundesthemen/sonderanalyse-2295276.html, last accessed 2020/07/20.

7. Erdsiek, D.: Unternehmen wollen auch nach der Krise an Homeoffice festhalten, http://ftp.zew.de/pub/zew-docs/brepikt/202002BrepIKT.pdf, last accessed 2020/11/27.

8. Bockstahler, M., Jurecic, M., Rief, S.: Working from home experience. An empirical study from the user perspective during the Corona pandemic. Off. 21 - Zukunft der Arbeit. (2020).

9. Song, Y., Gao, J.: Does Telework Stress Employees Out? A Study on Working at Home and Subjective Well-Being for Wage/Salary Workers. J. Happiness Stud. 21, 2649-2668 (2019).

10. Delanoeije, J., Verbruggen, M., Germeys, L.: Boundary role transitions: A day-to-day approach to explain the effects of home-based telework on work-to-home conflict and home-to-work conflict. Hum. Relations. 72, 1843-1868 (2019).

11. Agerfalk, P.J., Conboy, K., Myers, M.D.: Information systems in the age of pandemics: COVID-19 and beyond. Eur. J. Inf. Syst. 29, 203-207 (2020).

12. Sonnentag, S., Fritz, C.: Recovery from job stress: The stressor-detachment model as an integrative framework. J. Organ. Behav. 36, 72-103 (2015).

13. Cho, J., Ramgolam, D.I., Schaefer, K.M., Sandlin, A.N.: The Rate and Delay in Overload: An Investigation of Communication Overload and Channel Synchronicity on Identification and Job Satisfaction. J. Appl. Commun. Res. 39, 38-54 (2011).

14. Büchler, N., ter Hoeven, C.L., van Zoonen, W.: Understanding constant connectivity to work: How and for whom is constant connectivity related to employee well-being? Inf. Organ. 30, (2020).

15. Richter, A.: Locked-down digital work. Int. J. Inf. Manage. 55, 102157 (2020).

16. Leung, L., Zhang, R.: Mapping ICT use at home and telecommuting practices: A perspective from work/family border theory. Telemat. Informatics. 34, 385-396 (2017).

17. Boell, S.K., Cecez-Kecmanovic, D., Campbell, J., Cheng, J.E.: Advantages, challenges and contradictions of the transformative nature of telework: A review of the literature. In: Proceedings of the 19th Americas Conference on Information Systems (2013). 
18. Di Martino, V., Wirth, L.: Telework: A New Way of Working and Living. Int. Labour Rev. 129, 529-554 (1990).

19. Mann, S., Holdsworth, L.: The psychological impact of teleworking: Stress, emotions and health. New Technol. Work Employ. 18, 196-211 (2003).

20. Bloom, N., Liang, J., Roberts, J., Ying, Z.J.: Does Working from Home Work? Evidence from a Chinese Experiment. Q. J. Econ. 130, 165-218 (2015).

21. Weinert, C., Maier, C., Laumer, S., Weitzel, T.: Does teleworking negatively influence IT professionals? An empirical analysis of IT personnel's telework-enabled stress. In: Proceedings of the Conference on Computers and People Research (2014).

22. Dettmers, J., Bamberg, E., Seffzek, K.: Characteristics of extended availability for work: The role of demands and resources. Int. J. Stress Manag. 23, 276-297 (2016).

23. Diaz, I., Chiaburu, D.S., Zimmerman, R.D., Boswell, W.R.: Communication technology: Pros and cons of constant connection to work. J. Vocat. Behav. 80, 500508 (2012).

24. Fenner, G.H., Renn, R.W.: Technology-assisted supplemental work and work-to-family conflict: The role of instrumentality beliefs, organizational expectations and time management. Hum. Relations. 63, 63-82 (2010).

25. Golden, T.D.: Altering the Effects of Work and Family Conflict on Exhaustion: Telework During Traditional and Nontraditional Work Hours. J. Bus. Psychol. 27, 255269 (2012).

26. Suh, A., Lee, J.: Understanding teleworkers' technostress and its influence on job satisfaction. Internet Res. 27, 140-159 (2017).

27. Messenger, J.C., Gschwind, L.: Three generations of Telework: New ICTs and the (R)evolution from Home Office to Virtual Office. New Technol. Work Employ. 31, 195-208 (2016).

28. Meijman, T.F., Mulder, G.: Psychological aspects of workload. In: Drenth, P.J.D., Thierry, H., and De Wolff, C.J. (eds.) Handbook of work and organizational psychology. pp. 5-33. Psychology Press, Hove, England (1998).

29. Lundberg, U., Lindfors, P.: Psychophysiological reactions to telework in female and male white-collar workers. J. Occup. Health Psychol. 7, 354-364 (2002).

30. Sonnentag, S.: Psychological detachment from work during leisure time: The benefits of mentally disengaging from work. Curr. Dir. Psychol. Sci. 21, 114-118 (2012).

31. Mazmanian, M., Erickson, I.: The product of availability: Understanding the economic underpinnings of constant connectivity. In: Proceedings of the SIGCHI Conference on Human Factors in Computing Systems. pp. 763-772. ACM (2014).

32. Vartiainen, M., M., H., Koivisto, S., Mannonen, P., Nieminen, M.P., Ruohomäki, V., Vartola: Distributed and Mobile Work - Places, People and Technology. Otatieto, Helsinki (2007).

33. Jurecic, M., Rief, S., Stolze, D.: Office Analytics - Success Factors for Designing a Worktype-Based Working Environment. Fraunhofer IAO, Stuttgart (2018).

34. Weichbrodt, J., Schulze, H.: Homeoffice als Pandemie-Maßnahme - Herausforderungen und Chancen. In: Benoy, C. (ed.) COVID-19: Ein Virus nimmt Einfluss auf unsere Psyche. Einschätzungen und Maßnahmen aus psychologischer Perspektive. pp. 93-101. Kohlhammer, Stuttgart (2020).

35. Newport, C.: Deep Work: Rules for Focused Success in a Distracted World. Grand 
Central Publishing, New York, USA (2016).

36. Spataro, J.: The future of work - the good, the challenging \& the unknown, https://www.microsoft.com/en-us/microsoft-365/blog/2020/07/08/future-work-goodchallenging-unknown/, last accessed 2020/11/26.

37. Lansmann, S., Klein, S.: How much collaboration? Balancing the needs for collaborative and uninterrupted work. In: Proceedings of the 26th European Conference on Information Systems (2018).

38. Barley, S.R., Meyerson, D.E., Grodal, S.: E-mail as a source and symbol of stress. Organ. Sci. 22, 887-906 (2011).

39. Stephens, K.K., Mandhana, D.M., Kim, J.J., Li, X.: Reconceptualizing Communication Overload and Building a Theoretical Foundation. Commun. Theory. 27, 269-289 (2017).

40. Chung, C.J., Goldhaber, G.: Measuring communication load: A three-dimensional instrument. In: 41st Meeting of the International Communication Association (1991).

41. Cho, J.: Communication Load. In: Scott, C.R. and Lewis, L. (eds.) The International Encyclopedia of Organizational Communication. pp. 1-9. Wiley, West Sussex (2017).

42. Derks, D., Bakker, A.B.: Smartphone Use, Work-Home Interference, and Burnout: A Diary Study on the Role of Recovery. Appl. Psychol. 63, 411-440 (2014).

43. Cambier, R., Derks, D., Vlerick, P.: Detachment from work: A diary study on telepressure, smartphone use and empathy. Psychol. Belg. 59, 227-245 (2019).

44. Sonnentag, S., Fritz, C.: The Recovery Experience Questionnaire: Development and validation of a measure for assessing recuperation and unwinding from work. J. Occup. Health Psychol. 12, 204-221 (2007).

45. Cohen, S., Kamarck, T., Mermelstein, R.: A Global Measure of Perceived Stress. J. Health Soc. Behav. 24, 385-396 (1983).

46. Agarwal, R., Prasad, J.: A Conceptual and Operational Definition of Personal Innovativeness in the Domain of Information Technology. Inf. Syst. Res. 9, 204-215 (1998).

47. Feldt, T., Lintula, H., Suominen, S., Koskenvuo, M., Vahtera, J., Kivimäki, M.: Structural validity and temporal stability of the 13-item sense of coherence scale: Prospective evidence from the population-based HeSSup study. Qual. Life Res. 16, 483-493 (2007).

48. Kuckartz, U.: Qualitative Text Analysis. SAGE Publications, Los Angeles (2014).

49. Kenny, D.A., Kashy, D., Bolger, N.: Data analysis in social psychology. Oxford University Press, New York (1998).

50. Cooper, C.D., Kurland, N.B.: Telecommuting, professional isolation, and employee development in public and private organizations. J. Organ. Behav. 23, 511-532 (2002).

51. Tietze, S., Nadin, S.: The psychological contract and the transition from office-based to home-based work. Hum. Resour. Manag. J. 21, 318-334 (2011).

52. Piszczek, M.M.: Boundary control and controlled boundaries: Organizational expectations for technology use at the work-family interface. J. Organ. Behav. 38, 592611 (2017).

53. Nardi, B.A., Whittaker, S., Bradner, E.: Interaction and Outeraction: Instant Messaging in Action. Proc. ACM Conf. Comput. Support. Coop. Work. 79-88 (2000). 